\title{
Autobiographical memory: a clinical perspective
}

\author{
Nadja Urbanowitsch ${ }^{1}{ }^{*}$, Lina Gorenc ${ }^{1}$, Christina J. Herold ${ }^{1}$ and Johannes Schröder ${ }^{1,2}$ \\ ' Section of Geriatric Psychiatry, University of Heidelberg, Heidelberg, Germany \\ 2 Institute of Gerontology, University of Heidelberg, Heidelberg, Germany
}

Edited by:

Hans J. Markowitsch, University of

Bielefeld, Germany

\section{Reviewed by:}

Iris-Katharina Penner, University of

Basel, Switzerland

Thomas Leyhe, University of

Tübingen, Germany

*Correspondence:

Nadja Urbanowitsch, Section of Geriatric Psychiatry, University of Heidelberg, Voßstraße 4, 69115 Heidelberg, Germany

e-mail: nadja.urbanowitsch@med. uni-heidelberg.de
Autobiographical memory (ABM) comprises memories of one's own past that are characterized by a sense of subjective time and autonoetic awareness. Although ABM deficits are among the primary symptoms of patients with major psychiatric conditions such as mild cognitive impairment (MCl) and Alzheimer Disease (AD) or chronic schizophrenia large clinical studies are scarce. We therefore summarize and discuss the results of our clinical studies on ABM deficits in the respective conditions. In these studies ABM was assessed by using the same instrument - i.e., the Erweitertes Autobiographisches Gedächtnis Inven$\operatorname{tar}(E-A G I)$ - thus allowing a direct comparison between diagnostic groups. Episodic ABM, especially the richness of details was impaired already in $\mathrm{MCl}$ and in beginning AD. Semantic memories were spared until moderate stages, indicating a dissociation between both memory systems. A recency effect was detectable in cognitively unimpaired subjects and vanished in patients with AD. A similar pattern of deficits was found in patients with chronic schizophrenia but not in patients with major depression. These ABM deficits were not accounted for by gender, or education level and did not apply for the physiological ageing process in otherwise healthy elderly. In conclusion, ABM deficits are frequently found in $A D$ and chronic schizophrenia and primarily involve episodic rather than semantic memories. This dissociation corresponds to the multiple trace theory which hypothesized that these memory functions refer to distinct neuronal systems. The semi-structured interview E-AGI used to discern ABM changes provided a sufficient reliability measures, moreover potential effects of a number of important confounders could be falsified so far. These findings underline the relevance of ABM-assessments in clinical practice.

Keywords: autobiographical memory, semantic memory, episodic memory, mild cognitive impairment, Alzheimer's disease, chronic schizophrenia, hippocampus, multiple trace theory

\section{INTRODUCTION}

Autobiographical memory (ABM) refers to memories of an individual, which are characterized by a sense of subjective time and autonoetic awareness (Tulving, 1972, 2002) and entailed by feelings of emotional re-experience (Tulving, 1983; Tulving and Markowitsch, 1998; Markowitsch, 2003). Because of the interaction of episodic and semantic memory and the uniqueness to humans ABM is considered to be crucial for the continuity of the self and the development of personal identity, i.e., processes which are typically disturbed in patients with major psychiatric conditions such as Alzheimer's disease (AD) or chronic schizophrenia (Conway and Pleydell-Pearce, 2000; Cuervo-Lombard et al., 2007; Berna et al., 2012; Seidl et al., 2011; Herold et al., 2013). As a part of the declarative memory, ABM comprises a semantic plus an episodic domain. While semantic ABM involves general facts from different life time periods, episodic ABM includes biographic events with a richness of details and a feeling of re-experiencing when recalled.

According to Ribot's law (Ribot, 1881) remote memories are more resistant to brain damage than recent one. Ribot's law stands in opposition to the recency effect that implies a better consolidation of recent memories than remote ones. Declarative mnestic deficits are among the core symptoms of $\mathrm{AD}$ and usually go along with anterograde memory impairment in the initial phases and loss of remote memory following Ribot's gradient in the more advanced stages (Sagar et al., 1988; Dall'Ora et al., 1989; Kopelman, 1989; Greene and Hodges, 1996; Dorrego et al., 1999; Piolino et al., 2003; Hou et al., 2005; Leyhe et al., 2009). Two important theoretical approaches regarding the role of the hippocampus on ABM retrieval are the standard model of consolidation and the multiple trace theory (Squire and Alvarez, 1995; Nadel and Moscovitch, 1997). The first approach suggests that the function of the hippocampus in ABM is time-limited; hence, memories become gradually independent of the medial temporal lobe (MTL) in the course of time. In contrast, the multiple trace theory predicts that the recall process of the episodic autobiographical memories requires the hippocampal formation irrespective of how old the relevant memories are. The semantic memories, however, could be recalled independently of this structure and were subject to Ribot's gradient. The majority of studies support the multiple trace theory (Conway et al., 1999; Piolino et al., 2004; Viard et al., 2007). There are also reports of spared personal-semantic memory but impaired personal episodic memories without a temporal gradient in patients with MTL lesions (Viskontas et al., 2000; Steinvorth et al., 2005; Noulhiane et al., 2008). 
Autobiographical memory deficits are not specific to $\mathrm{AD}$ but were also described in mild cognitive impairment (MCI) and chronic schizophrenia. These changes do not only contribute to our understanding of the respective diseases but have the potential to facilitate clinical examination and diagnosis. However, the potential impact of important confounders, such as education, depressive mood, or the aging process as such needs to be addressed.

In the following we summarize and discuss findings from our studies on $\mathrm{ABM}$ deficits in $\mathrm{MCI}$ and $\mathrm{AD}$, major depression, and chronic schizophrenia with reference to normal aging.

\section{CLINICAL STUDIES METHODS}

Methodological details of the five studies conducted by our group as well as the description of sample characteristics are summarized in Table 1.

Autobiographical memory was investigated by using the Erweitertes Autobiographisches Gedächtnis Inventar (E-AGI) (Kopelman et al., 1990; Fast et al., 2007) - a semi-structured autobiographical interview based on the ABM Interview of Kopelman and colleagues. A previous version of the E-AGI was used in one study. Both, personal-semantic facts (SEM) as well as free recalled

Table 1 | Studies on ABM in major depression, $M C I, A D$, and chronic schizophrenia

\begin{tabular}{|c|c|c|c|c|c|c|}
\hline \multirow[t]{2}{*}{ Study } & \multirow{2}{*}{$\begin{array}{l}\text { Psychometric instruments/ } \\
\text { neuropsychological } \\
\text { assessment/MRI }\end{array}$} & \multicolumn{5}{|c|}{ Subjects } \\
\hline & & $\begin{array}{l}\text { Sample } \\
\text { size }\end{array}$ & Patients' groups & $\begin{array}{l}\text { Female/ } \\
\text { male }\end{array}$ & $\begin{array}{l}\text { Age (years): } \\
\text { mean (SD) }\end{array}$ & $\begin{array}{l}\text { Education (years): } \\
\text { mean (SD) }\end{array}$ \\
\hline \multirow{7}{*}{$\begin{array}{l}\text { Ahlsdorf } \\
\text { (2009) }\end{array}$} & Erweitertes Autobiographisches & $N=120$ & Depression $(n=30)$ & $21 / 9$ & $68.8(6.6)$ & $11.8(2.4)$ \\
\hline & $\begin{array}{l}\text { Gedächtnis Inventar (E-AGI), previous } \\
\text { version }\end{array}$ & & & & & \\
\hline & Mini mental state examination (MMSE) & & $\mathrm{MCl}(n=30)$ & $15 / 15$ & $70.2(5.8)$ & $12.3(3.3)$ \\
\hline & NEO five factor inventory (NEO-FFI) & & $\mathrm{AD}(n=30)$ & $18 / 12$ & $74.4(6.7)$ & $11.0(2.7)$ \\
\hline & Beck depression inventar (BDI) & & Healthy controls ( $n=30$ ) & $19 / 11$ & $66.9(5.9)$ & $15.2(3.3)$ \\
\hline & Geriatric Depression Scale (GDS) & & & & & \\
\hline & Apathy Evaluation Scale (self-rating) & & & & & \\
\hline \multirow{6}{*}{$\begin{array}{l}\text { Seidl et al. } \\
\text { (2011) }\end{array}$} & Erweitertes Autobiographisches & $N=239$ & Patients with $\mathrm{MCl}(n=33)$ & $21 / 12$ & $79.3(6.9)$ & \\
\hline & Gedächtnis Inventar (E-AGI) & & & & & \\
\hline & Global Deterioration Scale (GDS) & & Patients with mild AD $(n=35)$ & $26 / 9$ & $84.3(7.8)$ & \\
\hline & Mini mental state examination (MMSE) & & Patients with moderate AD $(n=56)$ & $49 / 7$ & $86.9(6.1)$ & \\
\hline & Neuropsychiatric inventory (NPI) & & Patients with severe AD $(n=74)$ & $64 / 10$ & $87.1(7.0)$ & \\
\hline & Apathy Evaluation Scale (AES-10) & & Healthy controls $(n=41)$ & $25 / 16$ & $76.0(4.7)$ & \\
\hline \multirow{6}{*}{$\begin{array}{l}\text { Berna et al. } \\
(2012)\end{array}$} & Erweitertes Autobiographisches & $N=395$ & $\mathrm{MCl}(n=63)$ & $29 / 34$ & $74.0(0.9)$ & $12.3(2.1)$ \\
\hline & Gedächtnis Inventar (E-AGI) & & & & & \\
\hline & Nürnberger-Alters-Inventar (NAl) & & Younger healthy controls $(n=194)$ & $90 / 104$ & $55.1(1.0)$ & $14.6(2.5)$ \\
\hline & Logical memory subtest (WMS-R) & & Older healthy controls $(n=138)$ & $73 / 65$ & $73.8(0.9)$ & $13.9(3.0)$ \\
\hline & Trail Making Test, Versions A and B (TMT & & & & & \\
\hline & A, TMT B) & & & & & \\
\hline \multirow{4}{*}{$\begin{array}{l}\text { Thomann } \\
\text { et al. (2012) }\end{array}$} & Erweitertes Autobiographisches & $N=53$ & $\mathrm{MCl}(n=15)$ & $8 / 7$ & $73.3(3.8)$ & $12.3(3.1)$ \\
\hline & Gedächtnis Inventar (E-AGI) & & & & & \\
\hline & Mini mental state examination (MMSE) & & Mild AD $(n=14)$ & $7 / 7$ & $73.7(5.2)$ & $11.4(3.0)$ \\
\hline & Magnetic resonance imaging (MRI) & & Healthy controls ( $n=24$ ) & $10 / 14$ & $72.8(3.3)$ & $13.8(3.6)$ \\
\hline \multirow{3}{*}{$\begin{array}{l}\text { Herold } \\
\text { et al. (2013) }\end{array}$} & Erweitertes Autobiographisches & $N=54$ & Schizophrenia ( $n=33$ ) & $10 / 23$ & $52.0(8.8)$ & $12.6(2.8)$ \\
\hline & Gedächtnis Inventar (E-AGI) & & & & & \\
\hline & Brief Psychiatric Rating Scale (BPRS) & & Healthy controls $(n=21)$ & $9 / 12$ & $53.7(8.0)$ & $13.9(2.1)$ \\
\hline
\end{tabular}

Scale for the Assessment of Positive

Symptoms (SAPS)

Scale for the Assessment of Negative

Symptoms (SANS)

Apathy Evaluation Scale (AES)

Bielefelder Famous Faces Test (BFFT)

Magnetic resonance imaging (MRI) 
autobiographical events (EP-F) of five different lifetime periods (preschool, primary school, secondary school, early adulthood, recent 5 years) are considered. One autobiographical event from each lifetime period had to be described in detail. The score of maximal 11 points was given considering the number of details of such an event (EP-D). According to Conway (Conway, 1996; Conway and Pleydell-Pearce, 2000) event-specific knowledge plays a central role to autobiographical remembering and is stored and encoded in a completely different way than knowledge about "general events" or "lifetime periods," which can be assigned to semantic autobiographical knowledge. To reduce the time necessary for the examination and to consider the restrictions due to the psychiatric conditions, the interview was modified and limited to the following three lifetime periods (primary school, early adulthood, recent 5 years - Figure 1) in four studies.

\section{STUDY 1: PSYCHOMETRIC PROPERTIES OF ABM ASSESSMENT AND EFFECTS OF DEPRESSED MOOD (AHLSDORF, 2009) \\ Group difference and effects of depressed mood}

When compared between the four diagnostic groups, SEM scores showed only minor, non-significant differences. In contrast, EP-F scores were significantly higher in healthy controls, patients with

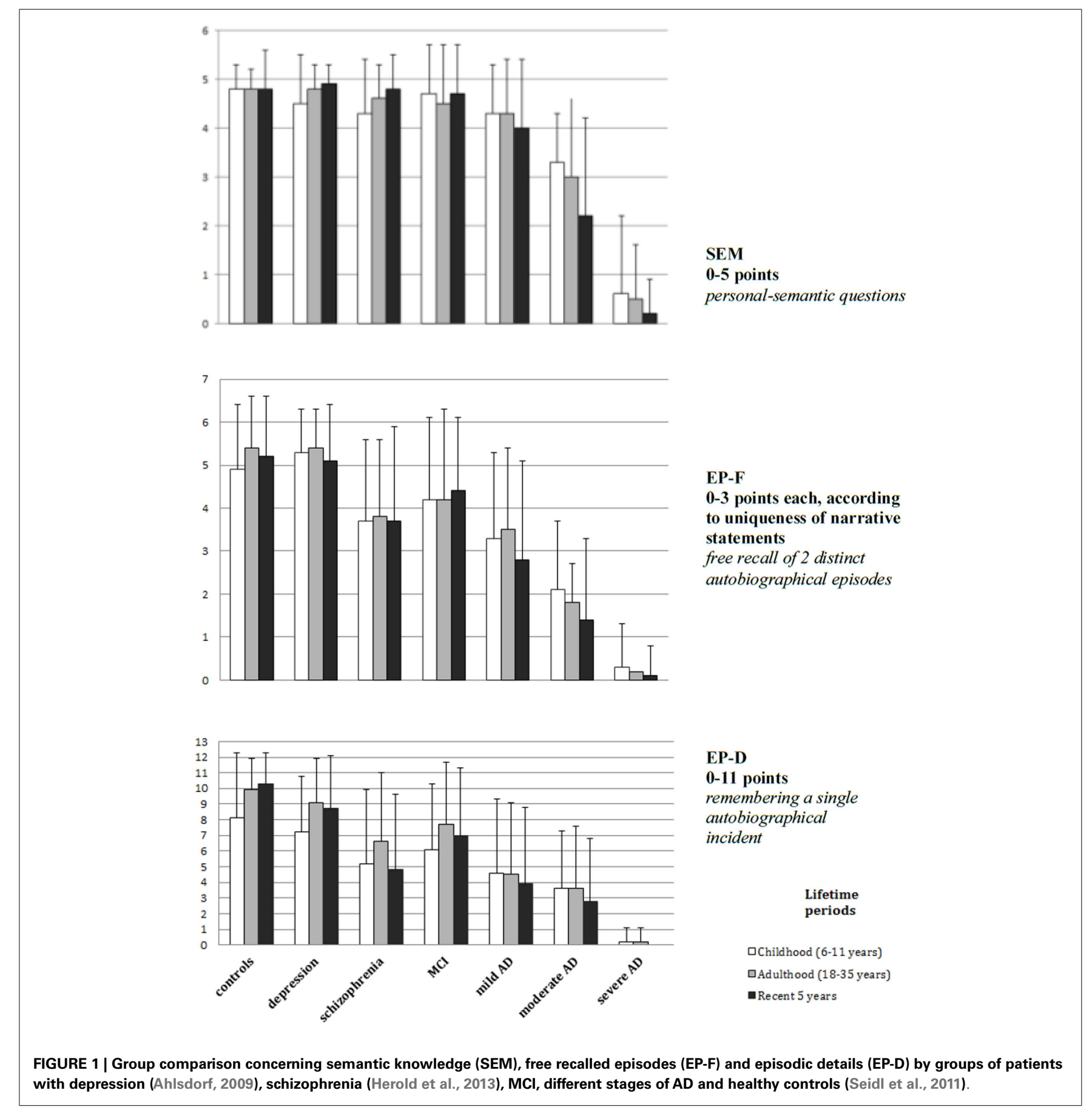


major depression and patients with $\mathrm{MCI}$ than in those with manifest AD. Similar results applied for the EP-D which were significantly higher in the healthy controls followed by patients with MCI and major depression than in those with manifest AD. Only marginally, non-significant differences in EP-D scores between healthy controls and patients with major depression could be found. The E-AGI total values diminished non-significantly in patients with major depression in comparison to healthy controls. The study yielded an important result in the comparison of the evaluation of memories. Patients with major depression were occupied with negative thoughts and estimated their memories more negative than patients with $\mathrm{AD}$.

\section{STUDY 2: ABM IN NURSING HOME RESIDENTS WITH MCI AND MANIFEST AD (SEIDL ET AL., 2011)}

Autobiographical memory was examined in patients with different stages of $\mathrm{AD}$ and $\mathrm{MCI}$, respectively, as well as in healthy controls (Table 1). Subjects were recruited in the framework of a large survey in nursing homes across Germany.

Results (Figure 1) demonstrated a progressive loss of ABM sum scores with increasing severity of dementia, which primarily involved episodic rather than semantic memories. When compared between controls, MCI, and mild AD diagnostic groups, SEM scores showed only minor, non-significant differences. Patients with moderate and severe AD displayed a significant reduction in SEM from the recent 5 years. Patients with moderate $\mathrm{AD}$ showed also a reduction for EP-F scores from the recent 5 years when compared to the childhood period whereas in healthy controls an inverse relationship was observed. This dissociation indicates that these memory functions are subserved by distinct neuronal systems as emphasized by the multiple trace hypothesis.

Further analyses of the temporal gradients in control subjects and MCI patients displayed a better memory performance from adulthood when compared to the childhood period. Both controls and patients with MCI showed lower EP-D scores for the childhood period.

In contrast, this recency effect was not found in patients with moderate $\mathrm{AD}$ suggesting an impact of the disease on the formation of recent memories.

\section{STUDY 3: ABM IN NORMAL AGING AND MCI (BERNA ET AL., 2012)}

Results confirmed a significant impairment of episodic ABM in MCI, but not in normal aging. Old-aged patients with MCI reached significantly lower scores than both Healthy Middle-Aged $(P<0.001)$ and Healthy Old-Aged $(P=0.02)$ subjects. Significant lower scores were also reached by Old-Aged patients with MCI compared with healthy Middle-Aged patients in the recent period $(P=0.004)$. Participants with MCI showed significantly lower scores than both control groups irrespective of age. These deficits were significantly correlated with verbal memory performances, but not with measures of executive functions.

\section{STUDY 4: HIPPOCAMPAL CHANGES AND ABM IN MCI AND AD (THOMANN ET AL., 2012)}

Autobiographical memory deficits were investigated with respect to hippocampal changes in patients with MCI $(n=15)$, patients with mild $\mathrm{AD}$ and cognitively unaffected control subjects $(n=24)$
(Table 1). Associations between ABM sum scores and hippocampal changes were explored using partial correlations, each of the significant correlations was confirmed by regional shape analyses. Results confirmed a significant ABM loss in the in early stages of $\mathrm{AD}$ and in MCI. Episodic, but not semantic ABM losses were associated with hippocampal atrophy mainly involving the left hippocampus. Right-sided hippocampal atrophy corresponded to reduced scores in the EP-F of the "childhood" lifetime period. These associations referred to the regional rather than to the global hippocampal changes which primarily affect the hippocampal head and body.

\section{STUDY 5: ABM DEFICITS IN CHRONIC SCHIZOPHRENIA (HEROLD ET AL., 2013)}

Autobiographical memory BM and hippocampal volume were assessed in 33 patients with chronic schizophrenia $(n=24)$ or patients with schizoaffective disorder $(n=9)$ and 21 healthy volunteers matched for age, gender, and education. The assessment of $\mathrm{ABM}$ was part of a large neuropsychological test battery, which also addressed verbal, short-term, and working memory as well as remote semantic memory. Psychopathological symptoms were rated on appropriate rating scales (Table $\mathbf{1}$ ).

When compared with the healthy controls, patients showed a significantly poorer recollection of episodic ABM as well as a trend toward a lower performance with respect to semantic ABM. Analysis of MRI data revealed lower volumes of left anterior and posterior hippocampus as well as of the right posterior hippocampus in the patients group.

Both, episodic and semantic ABM-scores were significantly correlated with the left hippocampal volume in the patient group. This association applied for both, the left anterior as well as the left posterior part of the hippocampus. These associations accounted for $16 \%$ of the variance of episodic ABM and $24 \%$ of the variance of semantic ABM with educational level considered as a covariate.

\section{DISCUSSION}

The present studies yielded the following main findings: (i) a confirmation that episodic rather than semantic ABM is impaired in major psychiatric conditions such as $\mathrm{AD}$ and chronic schizophrenia; (ii) evidence that this effect is not accounted for by potential confounding factors such as age, education, or depressed mood; and (iii) an indication that ABM deficits refer to hippocampal changes in both $\mathrm{AD}$ and chronic schizophrenia.

That episodic rather than semantic ABM is impaired already in the early stages of AD including MCI is made evident by a wealth of studies. This effect involves the recognition of past events and also includes the remembrance of recent experiences such as a consultation in the doctors' office and can facilitate clinical examination and diagnosis in early dementia (Donix et al., 2010). While semantic recall followed Ribot's law in patients with manifest dementia in all stages, episodic ABM recall showed this effect in patients with mild and moderate dementia only, since the respective deficits also included earlier life time periods.

A significant effect of potential confounding variables - in particular age, education, or depressed mood - on these findings was not confirmed. Age is a variable difficult to consider in any study on $\mathrm{AD}$ since the disease progresses with it. We therefore investigated 
potential age effects in a 332 otherwise healthy volunteers from two birth cohorts and demonstrated only minor non-significant episodic ABM differences with age. School education had to be considered as another potential confounder since this variable is a robust marker of cognitive reserve (Fratiglioni and Wang, 2007; Sattler, 2011; Schröder and Pantel, 2011). However, an effect of school education could not be confirmed (Berna et al., 2012). Depressive mood was primarily considered by Ahlsdorf (2009) who described an effect on the emotional content of the memories reported rather than their recollection per se. Depressed patients showed a significantly higher rate of negative valuations in both, semantic and episodic ABM. Along with this, Seidl et al. (2011) did not find the severity of ABM deficits to be significantly correlated with depressive mood although their sample of 239 nursing home residents provided a sufficient effect size.

Two of the studies summarized here - each one involving patients with MCI and AD or patients with chronic schizophrenia investigated ABM deficits with respect to MRI derived measures of hippocampal volume and shape. Irrespective of the diagnosis, episodic ABM deficits were associated with left hippocampal changes. An additional association of ABM deficits with right hippocampal changes was restricted to patients with MCI and AD. The respective associations clearly underline the importance of the hippocampus for the recollection of episodic ABM although these associations only accounted for a small proportion of the variance. Beginning in the early 1990s a wealth of neuroimaging studies found the hippocampus to be critically involved in MCI, AD, and chronic schizophrenia (Pantel et al., 1997; Heckers et al., 1998; Herold, 2011; Schröder and Pantel, 2011). Hence, it is plausible that the respective changes may result in similar deficits in both conditions. Differences refer to the extent of hippocampal changes and ABM deficits as well as to additional factors contributing to them. Further studies need to differentiate the association of hippocampal changes and ABM deficits by comparing hippocampal substructures for potential differences between these conditions or by considering additional clinical factors such as lifelong withdrawal, living without partnership, or long term hospitalization in patients with schizophrenia. Taken together, these finding conform with the multiple trace theory. Episodic ABM was already compromised in MCI and mild AD whereas recall of SEM was still preserved. This dissociation is generally referred to the hippocampus role for the recall of episodic but not semantic ABM since the former is already involved in the early and in the preclinical stages of AD (Pantel et al., 2003).

The results of our studies correspond to Conway's formal differentiation of event-specific knowledge and "general events" or "lifetime periods" (Conway, 1996; Conway and Pleydell-Pearce, 2000). From a more phenomenological standpoint, the failure of episodic remembrance in the more advanced stages of $\mathrm{AD}$ and schizophrenia causes a breakdown of subjective coherence and identity since life stories (McAdams, 1985) stop to be accessible nor retrievable anymore. This effect may be associated with psychopathological symptoms such as apathy which is another common features in both $\mathrm{AD}$ and chronic schizophrenia.

In conclusion the present studies underline the importance of episodic ABM changes in MCI, AD, and chronic schizophrenia, i.e., conditions which share hippocampal changes as a common feature. While deficits of episodic ABM are already present in the early stages of $\mathrm{AD}$, those of semantic $\mathrm{ABM}$ are confined to the more severe stages. In both, $\mathrm{AD}$ and chronic schizophrenia, ABM deficits were correlated with hippocampal changes. These findings demonstrate that $\mathrm{ABM}$ deficits can facilitate the clinical examination of patients with MCI, AD, and chronic schizophrenia.

\section{ACKNOWLEDGMENTS}

The studies reported here were supported in part by the Dietmar Hopp Foundation (Walldorf).

\section{REFERENCES}

Ahlsdorf, E. (2009). Differenzielle Untersuchungen zum Autobiographischen Gedächtnis. Ein Vergleich von gesunden älteren Menschen und Patienten mit leichter kognitiver Beeinträchtigung, beginnender Alzheimer Demenz sowie depressiver Episode. Hamburg: Verlag Dr. Kovac; Band, 145.

Berna, F., Schönknecht, P., Seidl, U., Toro, P., and Schröder, J. (2012). Episodic autobiographical memory in normal aging and mild cognitive impairment: a population-based study. Psychiatry Res. 200, 807-812. doi:10.1016/j.psychres. 2012.03.022

Conway, M. A. (1996). "Autobiographical knowledge and autobiographical memories," in Remembering Our Past: Studies in Autobiographical Memory, ed. D. C. Rubin (Dordrecht: Kluwer), 167-119.

Conway, M. A., and Pleydell-Pearce, C. W. (2000). The construction of autobiographical memories in the self-memory system. Psychol. Rev. 107, 261-228. doi:10.1037/0033-295X.107.2.261

Conway, M. A., Turk, D. J., Miller, S. L., Logan, J., Nebes, R. D., Meitzer, C. C., et al. (1999). A positron emission tomography (PET) study of autobiographical memory retrieval. Memory 7, 679-702. doi:10.1080/096582199387805

Cuervo-Lombard, C., Jovenin, N., Hedelin, G., Rizzo-Peter, L., Conway, M. A., and Danion, J. M. (2007). Autobiographical memory of adolescence and early adulthood events: an investigation in schizophrenia. J. Int. Neuropsychol. Soc. 13, 335-343. doi:10.1017/S135561770707035X

Dall'Ora, P., Della Salla, S., and Spinnler, H. (1989). Autobiographical memory. Its impairment in amnesic syndromes. Cortex 25, 197-217. doi:10.1016/S00109452(89)80037-1

Donix, M., Brons, C., Jurjanz, L., Poettrich, K., Winiecki, P., and Holthoff, V. A. (2010). Overgenerality of autobiographical memory in people with amnestic mild cognitive impairment and early Alzheimer's disease. Arch. Clin. Neuropsychol. 25, 22-27. doi:10.1093/arclin/acp098

Dorrego, M. F., Sabe, L., Garcia Cuerva, A., Kuzis, G., Tiberti, C., Boller, F., et al. (1999). Remote memory in Alzheimer's disease. J. Neuropsychiatry Clin. Neurosci. 11, 490-497.

Fast, K., Fujiwara, E., Schröder, J., and Markowitsch, H. J. (2007). Erweitertes Autobiographisches Gedächtnisinterview (E-AGI). Frankfurt: Harcourt.

Fratiglioni, L., and Wang, H.-X. (2007). Brain reserve hypothesis in dementia. J. Alzheimers Dis. 12, 11-22.

Greene, J. D., and Hodges, J. R. (1996). Identification of famous faces and famous names in early Alzheimer's disease. Relationship to anterograde episodic and general semantic memory. Brain 119, 111-128. doi:10.1093/brain/119.1.111

Heckers, S., Rauch, S. L., Goff, D., Savage, C. R., Schacter, D. L., Fischmann, A. J., et al. (1998). Impaired recruitment of the hippocampus during conscious recollection in schizophrenia. Nat. Neurosci. 1, 318-323. doi:10.1038/1137

Herold, C. J. (2011). “Zerebrale Korrelate des autobiographischen Gedächtnisses bei schizophrenen Psychosen," in Chronische Schizophrenien, eds J. Schröder and F. G. Brecht (Heidelberg: AKA GmbH), 85-105.

Herold, C. J., Lässer, M. M., Schmid, A. L., Seidl, U., Kong, L., Fellhauer, I., et al. (2013). Hippocampal volume reduction and autobiographical memory deficits in chronic schizophrenia. Psychiatry Res Neuroimaging 211, 189-194. doi:10.1016/j.pscychresns.2012.04.002

Hou, C. E., Miller, B. L., and Kramer, J. H. (2005). Patterns of autobiographical memory loss in dementia. Int. J. Geriatr. Psychiatry 20, 809-815. doi:10.1002/gps.1361

Kopelman, M. D. (1989). Remote and autobiographical memory, temporal context memory and frontal atrophy in Korsakoff and Alzheimer patients. Neuropsychologia 27, 437-460. doi:10.1016/0028-3932(89)90050-X

Kopelman, M. D., Wilson, B. A., and Baddeley, A. D. (1990). Autobiographical Memory Inventory. Bury St Edmunds: Thames Valley Test Company. 
Leyhe, T., Muller, S., Milian, M., Eschweiler, G. W., and Saur, R. (2009). Impairment of episodic and semantic autobiographical memory in patients with mild cognitive impairment and early Alzheimer's disease. Neuropsychologia 47, 2464-2469. doi:10.1016/j.neuropsychologia.2009.04.018

Markowitsch, H. J. (2003). "Memory: disturbances and therapy," in Neurological Disorders Course and Treatment, 2nd Edn, eds T. Brandt, L. Caplan, L. Dichgans, H. C. Diener, and C. Kennard (San Diego: Academic Press), 287-302.

McAdams, D. P. (1985). Power, Intimacy and the Life Story. Homewood, IL: Dorsey Press.

Nadel, L., and Moscovitch, M. (1997). Memory consolidation, retrograde amnesia and the hippocampal complex. Curr. Opin. Neurobiol. 7, 217-227. doi:10.1016/ S0959-4388(97)80010-4

Noulhiane, M., Piolino, P., Hasboun, D., Clemenceaue, S., Baulac, M., and Samson, S. (2008). Autonoetic consciousness in autobiographical memories after medial temporal lobe resection. Behav. Neurol. 19, 19-22.

Pantel, J., Kratz, B., Essig, M., and Schröder, J. (2003). Parahippocampal volume deficits in subjects with aging-associated cognitive decline. Am. J. Psychiatry 160, 379-382. doi:10.1176/appi.ajp.160.2.379

Pantel, J., Schröder, J., Schad, L. R., Friedlinger, M., Knopp, M. V., Schmitt, R., et al. (1997). Quantitative magnetic resonance imaging and neuropsychological functions in dementia of the Alzheimer type. Psychol. Med. 27, 221-229. doi:10.1017/S003329179600431X

Piolino, P., Desgranges, B., Belliard, S., Matuszewski, V., Lalevee, C., De la Sayette, V., et al. (2003). Autobiographical memory and autonoetic consciousness: triple dissociation in neurodegenerative diseases. Brain 126, 2203-2219. doi:10.1093/ brain/awg222

Piolino, P., Giffard-Quillon, G., Desgranges, B., Chetelat, G., Baron, J. C., and Eustache, F. (2004). Re-experiencing old memories via hippocampus: a PET study of autobiographical memory. Neuroimage 22, 1371-1383. doi:10.1016/j. neuroimage.2004.02.025

Ribot, T. (1881). Les maladies de la mémoire. Paris: Germer-Baillière.

Sagar, H. J., Cohen, N. J., Sullivan, E. V., Corkin, S., and Growdon, J. H. (1988). Remote memory function in Alzheimer's disease and Parkinson's disease. Brain 111, 185-206. doi:10.1093/brain/111.1.185

Sattler, C. (2011). Kognitive Reserve im Alter - Wechselwirkungen neuropsychologischer, sozialer und neurobiologischer Faktoren im Vorfeld demenzielle Erkrankungen. Heidelberg: Karl-Ruprecht-Universität.

Schröder, J., and Pantel, J. (2011). Die leichte kognitive Beeinträchtigung - Klinik, Diagnostik, Therapie und Prävention im Vorfeld der Alzheimer Demenz. Stuttgart: Schattauer-Verlag.

Seidl, U., Lueken, U., Thomann, P. A., Geider, J., and Schröder, J. (2011). Autobiographical memory deficits in Alzheimer's disease. J. Alzheimers Dis. 27, 567-574. doi:10.3233/JAD-2011-110014
Squire, L., and Alvarez, P. (1995). Retrograde amnesia and memory consolidation: a neurobiological perspective. Curr. Opin. Neurobiol. 5, 169-177. doi:10.1016/ 0959-4388(95)80023-9

Steinvorth, S., Levine, B., and Corkin, S. (2005). Medial temporal lobe structures are needed to re-experience remote autobiographical memories: evidence from H.M. and W.R. Neuropsychologia 43, 479-496. doi:10.1016/j.neuropsychologia. 2005.01.001

Thomann, P. A., Seidl, U., Brinkmann, J., Hirjak, D., Traeger, T., Wolf, R. C., et al. (2012). Hippocampal morphology and autobiographic memory in mild cognitive impairment and Alzheimer's disease. Curr. Alzheimer Res. 9, 000-000. doi:10.2174/156720512800492558

Tulving, E. (1972). "Episodic and semantic memory," in Organization and Memory, Vol. 1972, eds E. Tulving and W. Donaldson (New York: Academic Press), 381-403.

Tulving, E. (1983). Elements of Episodic Memory. Oxford: Clarendon Press.

Tulving, E. (2002). Episodic memory: from mind to brain. Annu. Rev. Psychol. 53 125. doi:10.1146/annurev.psych.53.100901.135114

Tulving, E., and Markowitsch, H. J. (1998). Episodic and declarative memory: role of the hippocampus. Hippocampus 8, 198-204. doi:10.1002/(SICI)10981063(1998)8:3<198::AID-HIPO2>3.3.CO;2-J

Viard, A., Piolino, P., Desgranges, B., Chetelat, G., Lebreton, K., Landeau, B., et al. (2007). Hippocampal activation for autobiographical memories over the entire lifetime in healthy aged subjects: an fMRI study. Cereb. Cortex 17, 2453-2467. doi:10.1093/cercor/bhl153

Viskontas, I. V., McAndrews, M. P., and Moscovitch, M. (2000). Remote episodic memory deficits in patients with unilateral temporal lobe epilepsy and excisions. J. Neurosci. 20, 5853-5857.

Conflict of Interest Statement: The authors declare that the research was conducted in the absence of any commercial or financial relationships that could be construed as a potential conflict of interest.

Received: 23 May 2013; accepted: 21 November 2013; published online: 10 December 2013.

Citation: Urbanowitsch N, Gorenc L, Herold CJ and Schröder J (2013) Autobiographical memory: a clinical perspective. Front. Behav. Neurosci. 7:194. doi: 10.3389/fnbeh.2013.00194

This article was submitted to the journal Frontiers in Behavioral Neuroscience.

Copyright (C) 2013 Urbanowitsch, Gorenc, Herold and Schröder. This is an open-access article distributed under the terms of the Creative Commons Attribution License (CC $B Y)$. The use, distribution or reproduction in other forums is permitted, provided the original author(s) or licensor are credited and that the original publication in this journal is cited, in accordance with accepted academic practice. No use, distribution or reproduction is permitted which does not comply with these terms. 